\title{
Microscrew implant as an orthodontic anchoring device
}

\author{
Mira Nurtania Supriadi, Eky Setiawan Soeria Soemantri, Ida Ayu Evangelina \\ Department of Orthodontic Faculty of Dentistry, Universitas Padjadjaran
}

\begin{abstract}
Microscrew implant is a new alternative of orthodontic anchoring device which is planted by simple surgery procedure into soft tissue and mandibular bone to utilize mandibular bone as an intraoral anchoring source. Microscrew implant is a small screw and consists of four components that can give various advantages, made from titanium material, and developed in various sizes and designs. Microscrew implant is strong, stable, and effective to be used as an absolute anchoring device in orthodontic treatment without losing the anchoring.
\end{abstract}

Key words: Anchoring, microscrew implant

\section{INTRODUCTION}

Anchoring is a defense that used to counteract the reaction force arising out of the orthodontic device active components force. Based on the third Newton Law, every action will cause a reaction with equal force and opposite direction, so every force made by active components will cause a reaction force. This force will have an effect on other tooth, so the tooth will experience undesirable movement. To prevent this, anchoring component is used as a defense to counteract the reaction force so the desired tooth movement will be maximized and the undesired tooth movement will be minimized. ${ }^{1,2}$

In general there are two types of anchoring device, extraoral anchoring device and intraoral anchoring device. The anchoring unit of extraoral anchoring device is located outside of the mouth. The extraoral anchoring device includes headgear and facemask. The anchoring unit of intraoral anchoring device is located inside the mouth. The intraoral anchoring device includes acrylic plate and intermaxillary elastic..$^{3,4}$

Both extraoral and intraoral anchoring devices have their advantages and disadvantages. The extraoral anchoring device is effective and stable, but it relies mostly on patient's cooperation. Usually patient refuses to use extraoral anchoring device because of the aesthetic and convenience reasons.

Intraoral anchoring device is not dependent on patient's cooperation, but the device is not stable, less efficient, and has limited capability. Because of those reasons, microscrew implant is introduced as a strong implant anchoring device to counteract the orthodontic force which is stable, effective, and does not depend on patient's cooperation.

According to Lin and Liou and Carano, et al. 5,6 , the advantages of microscrew implant are: (1) Strong and stable to counteract reciprocal force as well as allowing various types of tooth movement without losing anchoring; (2) Because microscrew has a small size, it is easier to determine the location of microscrew implant; (3) 
The placement and displacement of implant can be done by simple surgery procedure and not causing trauma on patient; (4) Application of force can be done soon after the placement of microscrew implant; (5) Less risk factor; (6) Cheaper than conventional implant; (7) Short treatment time; (8) Less dependency on patient; (9) Effective and efficient.

However, microscrew implant also has several disadvantages such $a s^{6}:(1)$ it can cause damage on anatomy structures like nerves, blood vessel, and root of tooth. (2) It can cause inflammation and irritation on the surrounding tissue. (3) It can be broken at the placement or displacement process.

\section{Microscrew implant design}

A lot of microscrew implant designs with various shape or size has been developed to maximize the advantages and minimize the side effect that can happen when using microscrew implant.

In general microscrew implant has these following components: ${ }^{5,6}$ (1) Head part with measurement is used to place and to connect orthodontic wire; (neck part is an isthmus

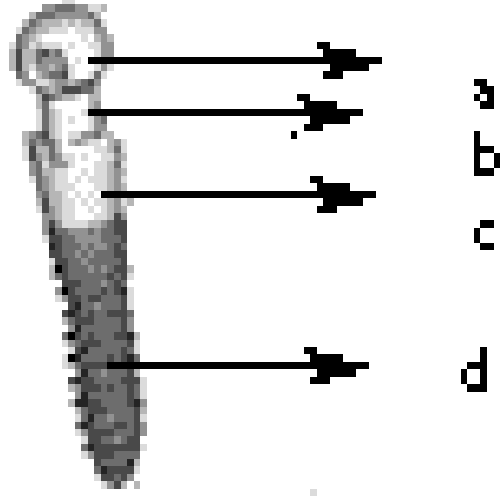

Figure 1. Part of implant microscrew (a) Head, (b) neck, (c) platform, (d) body
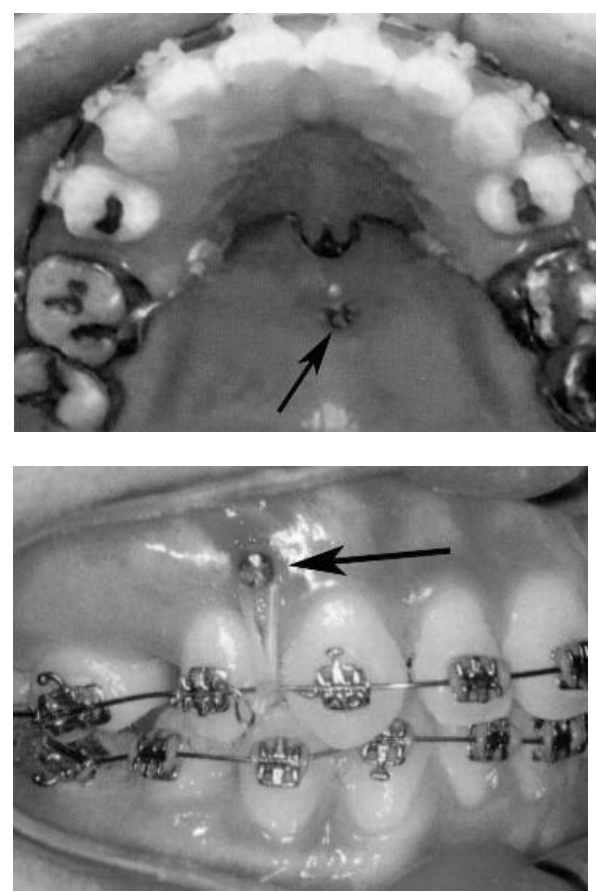
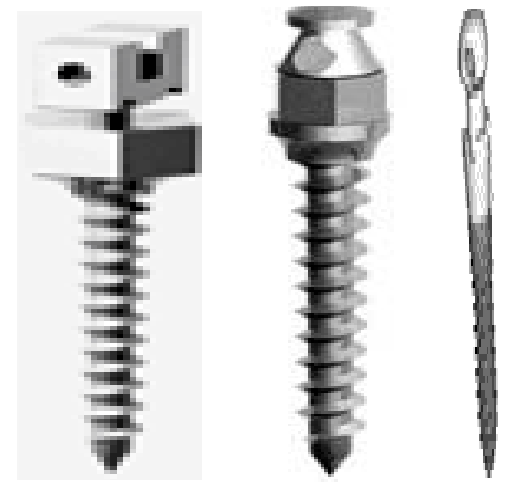

c.

Figure 2. Design variation microscrew implant. (a) Absoanchor bracket head type; (b) Absoanchor small head type c; (c) implant.
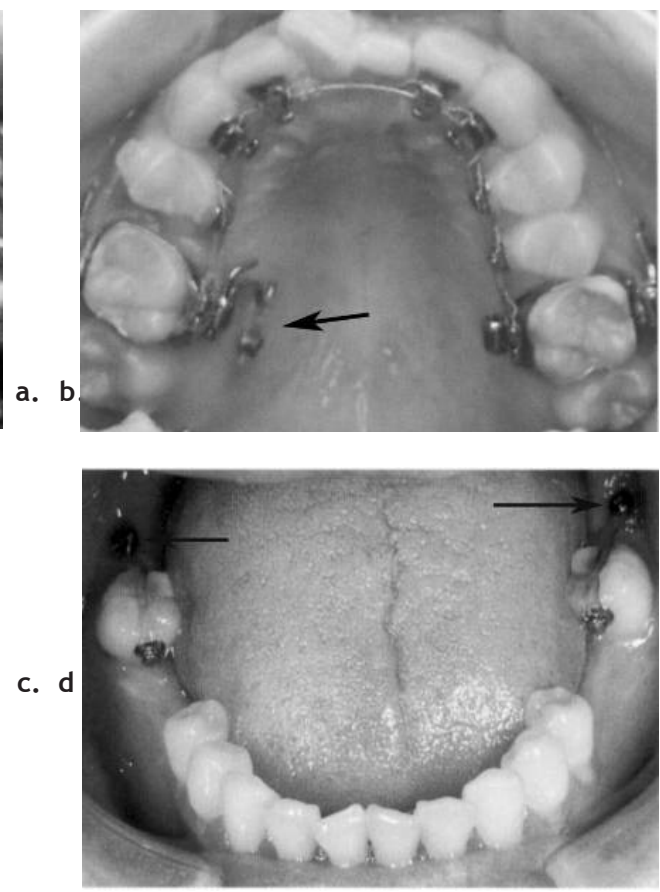

Figure 3. The location of microscrew implant placement

(a) Midpalatal, (b) Interadicular palatal bone between first molar and second molar of maxillary, (c) Interadicular bucal bone between canines and premolar of maxillary, (d) Retromolar of mandible. 
between head part and platform part that is used for elastic anchoring, Nickel Titanium Coil Spring, and other devices (3) Platform part is consist of three sizes $(1 \mathrm{~mm}, 2 \mathrm{~mm}, 3 \mathrm{~mm})$ and used on different soft tissue thickness on different microscrew implant placement site. The smooth surface helps the injury healing process on peri implant tissue and avoids gingival irritation; (4) Body part has parallel self-drilling form that produce mechanical retention.

Various microsrew implants with different diameter and length have been developed. The diameter of microscrew implant varies from $1 \mathrm{~mm}$ to $2.3 \mathrm{~mm}$, while the length varies from $4 \mathrm{~mm}$ to $17 \mathrm{~mm}$. The selection of microscrew implant diameter is based on the size of available space for microscrew implant placement and also based on the amount of force needed. The selection of microscrew implant length, however, is based on the quality of cortical bone, i.e. the thickness and density of cortical bone. Cortical bone of the maxillary is thinner and less dense than the mandible, so it is suggested to use longer microscrew implant than the implant used on mandible. ${ }^{8}$

\section{Microscrew implant placement site}

One advantages of microscrew implant is the small size and variation, so it is easier to choose the microscrew implant placement site. The selection of microscrew implant placement site is also related to retention due to the fact that the retention of microscrew implant is obtained from mechanical locking between microscrew implant with surrounding bones and the stability depends on the available bone thickness and density. ${ }^{7,9}$

There are some locations that can be used to place microscrew implant. Microscrew implant on the maxillary is placed on the following locations 5,6 : (1) Interadicular bucal bone; (2) Interadicular palatal bone; (3) Midsagital palatum region; (4) Paramedian palatum region;
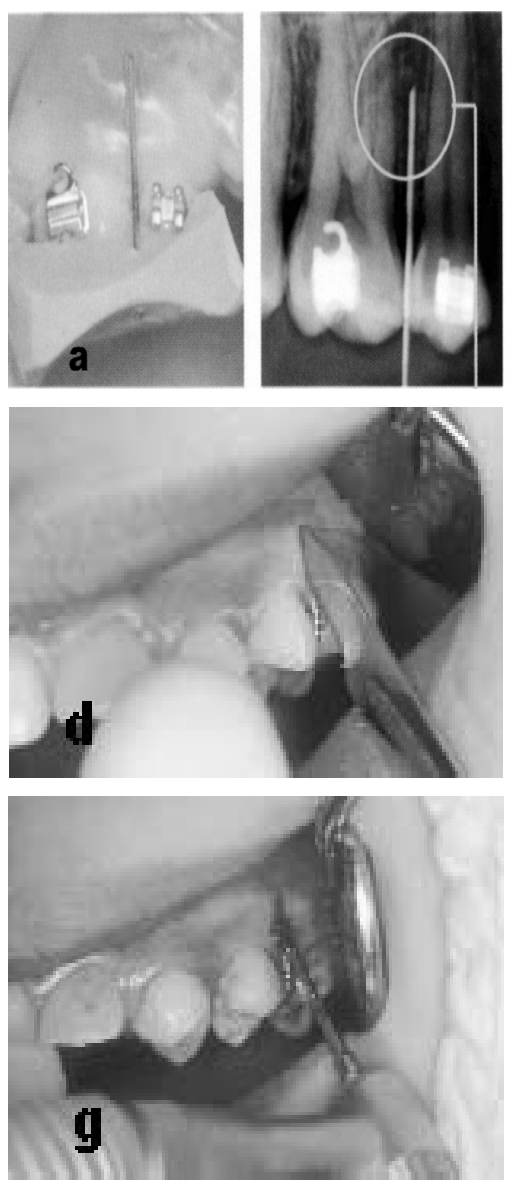
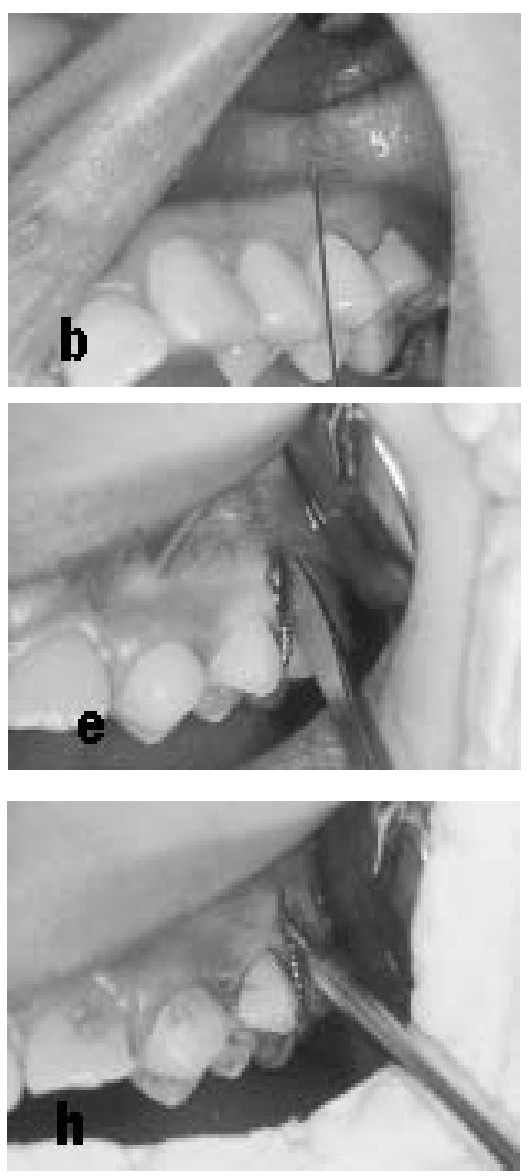
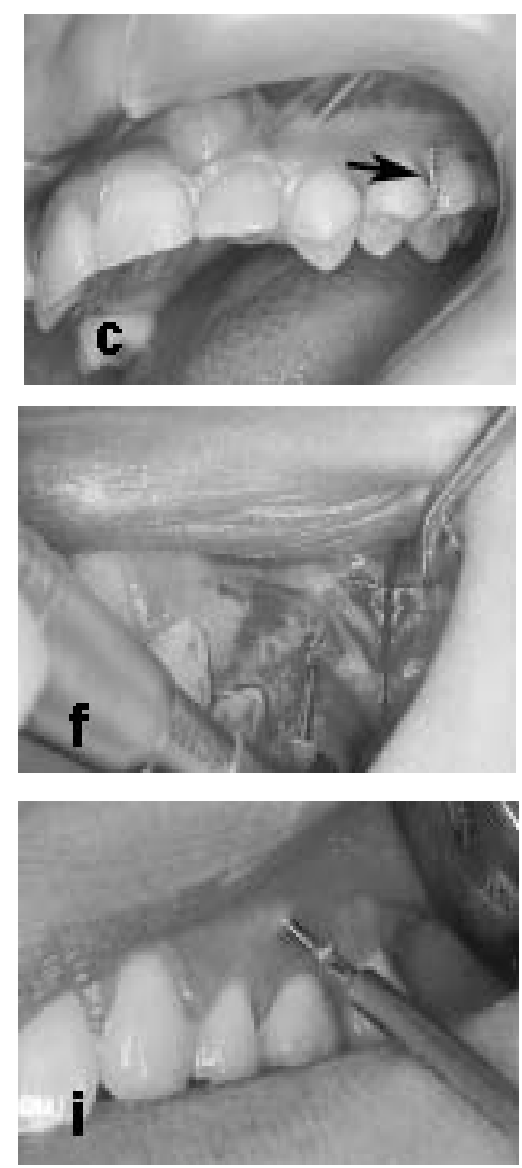

Figure 4. Microscrew implant placement procedure. (a) X-ray film to evaluate microscrew placement location; (b) Local anesthesia on the surgery location; (c) Brass wire placement (d) Vertical incision for preinstall flape. Flap using elevator preinstall (f) Signing the insertion point using round bur (g) Drilling using pilot drill (h) Microscrew placement by manual screw driver; (I) Microscrew displacement using manual key. 
(5) Extraction space; (6) Edentulous alveolar ridge. Microscrew implant on the mandible can be placed on the following locations: (1) Interadicular bucal bone; (2) Interadicular lingual bone; (3) Retromolar pad; (4) Extraction space; and (5) Edentulous alveolar ridge.

\section{Microscrew Implant Placement Procedure}

One advantage of microscrew implant is the simple placement procedure and does not cause trauma on patient ${ }^{5,6,9}$ : Before surgery, $\mathrm{X}$ ray photo is made to evaluate the microscrew implant placement site; Local anesthetic infiltration is done on surgery location; Place a brass wire on the surgery location as a guidance when doing gingival incision and when drilling the microscrew placement site using pilot drill; Surgery procedure depends on the selection of the microscrew placement site. (a) If it is on fixed gum, flap gingival is not needed (b) If it is on the alveolar mucosa is selected, vertical or horizontal incision is done on mucogingival junction and then mucoperiosteal flap is done; Make a dent using round drill device for stabilization when drilling with pilot drill device; Make a hole using pilot drill device with low speed together with normal saline irrigation to avoid bone necrosis resulted from heat of drilling process; Place the microscrew on the available hole using manual screwdriver; For microscrew implant placed on mucosa alveolar, the wound is irrigated with normal saline before stitching the flap; For microscrew implant placed on fixed gum, the application of force can be done directly. However, for microscrew placed on mucosa alveolar, it is better to wait until the wound healing process finished before the application of force is done to avoid infection.

\section{Microscrew implant material}

The materials normally used as microscrew implant material are pure titanium and alloy titanium. Pure Titanium is $\mathrm{TiO} 2$ contain $99.5 \%$ of Titanium and $0.5 \%$ of other materials such as $0.1 \%$ of Carbon, $0.4 \%$ of Oxygen, $0.05 \%$ of Nitrogen, and $0.5 \%$ of Fe. But the alloy titanium, Ti6Al4V contain $88-90 \%$ of titanium, $0.08 \%$ of Carbon, $0.2 \%$ of Oxygen, $0.05 \%$ of Nitrogen, $0.25 \%$ of $\mathrm{Fe}, 5.5$ 6.75\% of Aluminum and $3.5-4.5 \%$ of Vanadium). Titanium material usually used as microscrew implant material because it has biocompatible nature, it does not damage body tissue and also cannot be damaged by body tissue, nontoxic, corrosion proof, does not cause neoplasm, allergy, and immunology reaction.

It is mechanically stable, light, can counteract the orthodontic force and can counteract mastication force. ${ }^{11}$

\section{CONCLUSION}

Microscrew implant is a new anchoring device alternative in orthodontic treatment. It is made from titanium material, placed in bone using simple surgical procedure, and it is developed in various form, size, and design to maximize the advantages and minimize side effect that could arise from using microscrew implant. The selection of microscrew implants variant can be adjusted with needs, such as the size of available space, the amount of force needed, quality of bone i.e. thickness and density of available bone.

\section{REFERENCES}

1. Proffit WR. Contemporary Orthodontics. 3rd ed. Missouri: The CV. Mosby Co; 2000. p. 30810.

2. Isaacson KG, Muir JD, Reed RT. Removable orthodontics appliances. oxford: ButterworthHeinemann Ltd; 2002. p. 39-43.

3. Williams JK, Cook PA, Isaacson KG, et al. Fixed orthodontic apliances: principles \& practice. oxford : Butterworth-Heinemann Ltd; 1995. p. 7-14,53-75.

4. Kusnoto $\mathrm{H}$. Diagnosis dan rencana perawatan serta aplikasi alat ortodonti cekat. Cetakan kedua. Jakarta: Fakultas kedokteran Gigi Universitas Trisakti; 1996. p. 37-43.

5. Lin JCY, Liou EJW. A new bone screw for orthodontic anchorage. J Clin Orthod 2003; 37: 676-81.

6. Carano A, Velo S, Leone P, et al. Clinical aplications of the miniscrew anchorage system. $\mathrm{J}$ Clin Orthod 2005;39:9-24.

7. Chung KR, Kim SH, Kook YA. The C-orthodontic micro-implant. J Clin Orthod 2004;38:478-86.

8. Kyung HM, Park HS, Bae SM, et al. Development of orthodontic micro-implants for intraoral anchorage. J Clin Orthod. 2003; 37:321-8. 
9. Park HS, Bae SM, Kyung HM, dkk. Simultaneous incisor retraction dan distal molar movement with microimplant anchorage. World J Orthod. 2004;5:167-71.
10. Favero L, Brollo P, Bressan E. Orthodontic anchorage with specific fixtures: related study analysis. Am J Orthod Dentofacial Orthop 2002;122:84-94. 